Original Paper

\title{
Targeting Voltage-Dependent Calcium Channels with Pregabalin Exerts a Direct Neuroprotective Effect in an Animal Model of Multiple Sclerosis
}

\author{
Petra Hundehege ${ }^{a}$ Juncal Fernandez-Ortha Pia Römera Tobias Ruck ${ }^{a}$ \\ Thomas Müntefering ${ }^{a}$ Susann Eichler ${ }^{a}$ Manuela Cerina ${ }^{a} \quad$ Lisa Eppinga \\ Sarah Albrecht ${ }^{a}$ Amélie F. Menke ${ }^{a}$ Katharina Birkner ${ }^{b}$ Kerstin Göbela \\ Thomas Budde $^{c}$ Frauke Zipp ${ }^{b}$ Heinz Wiendla Ali Gorji ${ }^{d}$ Stefan Bittner \\ Sven G. Meuth ${ }^{\mathrm{a}}$ \\ aNeurology Department with Institute of Translational Neurology, University of Münster, ${ }^{b}$ Department \\ of Neurology, Focus Program Translational Neuroscience (FTN) and Immunotherapy (FZI), Rhine Main \\ Neuroscience Network (rmn2), University Medical Center of the Johannes Gutenberg University Mainz, \\ Institute of Physiology I, University of Münster, ${ }^{d}$ Neurology Department with Institute of Translational \\ Neurology and Neurosurgery Department, University of Münster, Germany
}

\section{Key Words}

Multiple sclerosis $•$ Pregabalin $•$ Experimental autoimmune encephalomyelitis $\bullet$ Neuroprotection

\begin{abstract}
Background/Aims: Multiple sclerosis (MS) is a prototypical autoimmune central nervous system (CNS) disease. Particularly progressive forms of MS (PMS) show significant neuroaxonal damage as consequence of demyelination and neuronal hyperexcitation. Immuno-modulatory treatment strategies are beneficial in relapsing MS (RMS), but mostly fail in PMS. Pregabalin (Lyrica $\left.{ }^{\circledR}\right)$ is prescribed to MS patients to treat neuropathic pain. Mechanistically, it targets voltage-dependent $\mathrm{Ca}^{2+}$ channels and reduces harmful neuronal hyperexcitation in mouse epilepsy models. Studies suggest that GABA analogues like pregabalin exert neuroprotective effects in animal models of ischemia and trauma. Methods: We tested the impact of pregabalin in a mouse model of MS (experimental autoimmune encephalomyelitis, EAE) and performed histological and immunological evaluations as well as intravital two-photon-microscopy of brainstem EAE lesions. Results: Both prophylactic and therapeutic treatments ameliorated the clinical symptoms of EAE and reduced immune cell infiltration into the CNS. On neuronal level, pregabalin reduced long-term potentiation in hippocampal brain slices indicating an impact on mechanisms of learning and memory. In contrast, T cells, microglia and brain endothelial cells were unaffected by pregabalin. However, we found a direct impact of pregabalin on neurons
\end{abstract}

P. Hundehege, J. Fernandez-Orth, S. Bittner and S.G. Meuth contributed equally to this paper. P. Hundehege and J. Fernandez-Orth share first authorship; S. Bittner and S. G. Meuth share last authorship. 
during CNS inflammation as it reversed the pathological elevation of neuronal intracellular $\mathrm{Ca}^{2+}$ levels in EAE lesions. Conclusion: The presented data suggest that pregabalin primarily acts on neuronal $\mathrm{Ca}^{2+}$ channel trafficking thereby reducing $\mathrm{Ca}^{2+}$-mediated cytotoxicity and neuronal damage in an animal model of MS. Future clinical trials need to assess the benefit for neuronal survival by expanding the indication for pregabalin administration to MS patients in further disease phases.

\section{Introduction}

Multiple sclerosis (MS) is an autoimmune disorder of the central nervous system (CNS) representing the primary cause of neurological disability in young adults in the Western world [1,2]. The initiation of the pathogenesis is characterized by the infiltration of auto-reactive immune cells into the CNS leading to inflammatory lesions consequently inducing extensive demyelination and neurodegeneration [1]. Treatment strategies modifying the immune system response were found beneficial, but with an exception of the B-cell depleting drug Ocrelizumab, these drugs fail to ameliorate neurodegeneration and thereby disability progression in PMS [3, 4]. Suitable drugs that promote neuronal survival in autoimmune inflammatory disorders are urgently needed. In this regard, ion channels are known to be interesting targets for the treatment of MS and other immunological diseases. Among them, blockers of voltage-gated sodium channels have been considered potential therapeutic targets for the treatment of MS, as they were shown to exert a neuroprotective effect and a reduction of the immune cell infiltration in mice [5] as well as an improved motor coordination and cerebellarlike symptoms in rodents [6,7]. However, as the other treatment strategies, these drugs were unsuccessful as they showed worsen clinical deficits and harmful effects in the animal model of MS [8].

Glutamate excitotoxicity, a phenomenon due to an excessive amount of glutamate resulting in cell death, could be a link between inflammatory and neurodegenerative processes evident in MS [9]. Inhibition of voltage-gated calcium channels (VGCCs) is a potential neuroprotective mechanism against excitotoxicity [10-12], and pregabalin (Lyrica ${ }^{\circledR}$ ) could be the key to overcome autoimmune neurodegeneration in diseases like MS. Chemically, pregabalin belongs to the group of gabapentinoids, which are analogues of the inhibitory neurotransmitter $\gamma$-aminobutyric acid (GABA) [13], and instead of binding to GABA receptors it binds to two isoforms of the auxiliary $\alpha 2 \delta$ subunit (gene names: Cacna2d1 and Cacna2d2) of VGCCs [14]. $\alpha 2 \delta$ subunits play an important role in channel folding and consequently in the trafficking of channels to the plasma membrane $[15,16]$. The binding of pregabalin to the $\alpha 2 \delta$ subunit of the VGCC inhibits channel trafficking leading to a reduced $\mathrm{Ca}^{2+}$ inward current. In neurons, this subsequently induces a reduction of neurotransmitter release from the presynapse [17, 18]. Under pathological conditions in animal seizure models, this effect reduces neuronal hyperexcitability and abnormal synchronization [18].

Nowadays gabapentinoids are not only used as antiepileptics but also for the treatment of other indications, including neuropathic pain in MS patients. Due to the existence of numerous variants of its pore-forming $\alpha 1$ subunit, as well as its auxiliary $\beta$ and $\alpha 2 \delta$ subunits, VGCCs are organized in complex protein assemblies $[19,20]$ in three different subfamilies [ $\mathrm{Ca}_{\mathrm{v}} 1\left(\mathrm{Ca}_{\mathrm{v}} 1.1-\mathrm{Ca}_{\mathrm{v}} 1.4\right), \mathrm{Ca}_{\mathrm{v}} 2\left(\mathrm{Ca}_{\mathrm{v}} 2.1-\mathrm{Ca}_{\mathrm{v}} 2.3\right)$ and $\mathrm{Ca}_{\mathrm{v}} 3\left(\mathrm{Ca}_{\mathrm{v}} 3.1-\right.$ $\left.\left.\mathrm{Ca}_{\mathrm{v}} 3.3\right)\right] . \mathrm{Ca}_{\mathrm{v}} 1$ and $\mathrm{Ca}_{\mathrm{v}} 2$ channels are capable of forming functional channels together with one of the four different auxiliary $\alpha 2 \delta$ subunits $[21,22]$. These subfamilies are known to be expressed in the plasma membrane of excitable and non-excitable cells (e.g. neurons, muscle, glial cells) [23-26] while there is a debate in the literature concerning their functional expression in various types of immune cells, including B- and T-lymphocytes [27]. 
Interestingly, besides its well-known therapeutic spectrum, there are hints pointing to a direct neuroprotective effect of pregabalin [28-31]. In this regard, gabapentin was found to effectively reduce acute seizures and injury after ischemia in mice $[29,31]$. Furthermore, gabapentin demonstrated similar neuroprotective effects as methylprednisolone in the early phase of spinal cord injury [28]. In a rat model of facial nerve avulsion, pregabalin administration led to better neuronal survival [30]. If these findings hold true, they might argue for an expansion of pregabalin's therapeutic spectrum to autoimmune neurodegeneration diseases, like MS. Here, we make use of an animal model of MS, the experimental autoimmune encephalomyelitis (EAE), to examine whether pregabalin exerts an effect apart from neuropathic pain reduction in MS pathophysiology.

\section{Material and Methods}

Mice

Male and female C57BL/6J WT mice were purchased from Charles River Laboratories (Sulzfeld, Germany). Mice were kept under IVC (Individually Ventilated Cages) animal housing conditions.

Induction and evaluation of active experimental autoimmune encephalomyelitis

Active EAE was induced by immunization of 8 - 10-week-old female wild type (WT; C57BL/6J) mice with myelin oligodendrocyte glycoprotein 35-55 ( $\mathrm{MOG}_{35-55}$ ) peptide (Charité, Berlin, Germany). The animals were subcutaneously immunized with $200 \mu \mathrm{g}$ of mouse MOG $_{35-55}$ peptide emulsified in $200 \mu \mathrm{l}$ complete Freund's adjuvant (Sigma-Aldrich GmbH, Steinheim, Germany) containing $200 \mu \mathrm{g}$ Mycobacterium tuberculosis (strain H37 Ra; Becton, Dickinson and Company (BD), Sparks, MD, USA). Pertussis toxin (PTx; 400 ng in $200 \mu \mathrm{l} \mathrm{PBS}$; Enzo Life Sciences, Farmingdale, NY, USA) was injected intraperitoneally (i.p.) on the day of immunization (day 0 ) and 2 days after immunization. The animals belonging to the prophylactic group (Preg (prophylactic)) were treated daily with i.p. injections of pregabalin $\left(30 \mathrm{mg}^{*} \mathrm{~kg}^{-1} \mathrm{BW}\right.$ according to the daily maximum dose for humans, Pfizer, NY, USA) starting 1 day after MOG $_{35-55}$ immunization, while the control groups (Ctrl) where injected with the respective vehicle $(0.9 \% \mathrm{NaCl})$. The therapeutic treatment (Preg (therapeutic)) started at day 15. All animals were kept under standard conditions and had access to water and food ad libitum. The clinical course of EAE was monitored daily using the following score system: grade 0 , no abnormality; grade 1 , limp tail tip; grade 2, limp tail; grade 3, moderate hindlimb weakness; grade 4, complete hindlimb weakness; grade 5, mild paraparesis; grade 6, paraparesis; grade 7, heavy paraparesis or paraplegia; grade 8, tetraparesis; grade 9, quadriplegia or premoribund state; or grade 10, death. Groups were age-, weight-, and sex-matched and mice were randomly assigned to control vs. treatment groups. The mean cumulative score was calculated for each group as the sum of the daily scores overall animals from day 0 or disease maximum $\left(\mathrm{d}_{\text {max }}\right)$ until the end of the experiment divided by the number of animals in the respective group. Animals with score $>7$ or when weight loss exceeded $20 \%$ of the initial body weight were taken out of the experiment, and the last score observed was assigned for the remainder of the experiment.

\section{Histology}

Mice were transcardially perfused with phosphate-buffered saline (PBS, Sigma-Aldrich GmbH) before removing spinal cords and embedded in Tissue-Tek optimum cutting temperature (OCT) compound (Miles Laboratories, Elkhart, IN, USA). $10 \mu \mathrm{m}$-thin sections from the lumbar region were stained with haemtoxylin and eosin (HE) and Luxol fast blue (LFB)-periodic acid Schiff myelin according to the standard procedures. All stainings were examined by microscopy (Axiophot2, Zeiss, Oberkochen, Germany) with a charge-coupled device camera (Zeiss, Oberkochen, Germany) and analyzed in a blinded manner using Axiovision (Zeiss) and also Image J software (National Institute of Health, Bethesda, USA). For quantification, inflammatory foci (HE) and demyelinated areas (LFB) were measured on three slices of six mice per group and the ratio was calculated.

\section{Cell isolation}

Single-cell suspensions of mouse spleens were prepared from naïve, 8 - 12-week-old female C57BL/6J or EAE animals. EAE mice were either euthanized at $d_{\max }\left(\sim 15\right.$ days after the induction of EAE, $\left.d_{\text {max }}\right)$ or at the 
end of the disease $\left(d_{\text {end }}\right)$ [32]. Spleen tissues were homogenized and strained through a $40 \mu \mathrm{m}$ nylon filter (BD Biosciences, Heidelberg, Germany). The homogenates were rinsed with washing medium (Dulbecco's Modified Eagle's Medium, \#31966-021, DMEM, Invitrogen) containing $1 \%$ fetal bovine serum (FBS, ScienCell Research Laboratories, Carlsbad, CA, USA), 1 \% glutamine (\#25030, Gibco Life Technologies), and $1 \%$ antibiotics (P4333, Penicillin/Streptomycin, Sigma-Aldrich), and were shortly resuspended in erythrocyte lysis buffer ( $150 \mathrm{mM} \mathrm{NH}_{4} \mathrm{Cl}, 10 \mathrm{mM} \mathrm{KHCO}{ }_{3}, 0.1 \mathrm{mM}$ ethylenediaminetetraacetic acid [EDTA]; pH 7.3). All immunomagnetic cell separations were performed using appropriate magnetic bead-based separation kits. Cells were cultured in DMEM media and, for splenocyte stimulation, cells were activated for 2 days with 3 $\mu \mathrm{g}^{*} \mathrm{ml}^{-1} \mathrm{CD} 3$ and $1 \mu \mathrm{g}^{*} \mathrm{ml}^{-1}$ soluble CD28-specific (clone 37.51; BD) antibodies.

\section{Flow cytometry}

For the detection of CNS-infiltrating immune cells, single-cell suspensions from murine spinal cords were stained for 30 minutes at $4{ }^{\circ} \mathrm{C}$ with different fluorescently labelled monoclonal antibodies $(1: 200$ in PBS containing $0.1 \% \mathrm{NaN}_{3}$ and $0.1 \% \mathrm{BSA}$ ): CD4 (clone RM4-5, BioLegend), CD8a (clone 53-6.7, BioLegend), CD11c (clone N418, BioLegend), CD45R/B220 (clone RA3-6B2, BD), CD45 (clone 30-F11, BioLegend) and CD11b (clone M1/70, eBioscience). Corresponding isotypes were used as controls. Stained cells were assayed on a Gallios flow cytometer using Kaluza Analysis Software (Beckman Coulter, Krefeld, Germany) and presented using GraphPad Prism (GraphPad Software Inc).

\section{ELISA and proliferation assay}

Splenocytes were cultured for 2 days and stimulated with $10 \mathrm{mg}^{*} \mathrm{ml}^{-1}$ of the antigen $\mathrm{MOG}_{35-55^{*}}$. Cytokine levels were measured in the supernatants using a IFN- $\gamma$ ELISA kit (R\&D Systems, Peprotech, Hamburg, Germany) according to the manufacturer's instructions. To assess splenocyte proliferation, cells were labelled with eFluor670 according to the manufacturer's instructions (\#65-0840-85, Cell Proliferation Dye eFluor 670, Thermo Fisher Scientific), and afterwards cultured for 4 days at $37^{\circ} \mathrm{C}$ and $10 \% \mathrm{CO}_{2}$. The proliferation was assessed via flow cytometry (Beckman Coulter, Krefeld, Germany).

\section{rRT-PCR}

RNA was purified using TRIzol reagent (Life Technologies) and semiquantitative reverse transcription polymerase chain reaction (RT-PCR) was performed as previously described [33] by using TaqMan Gene Expression Assays (Life Technologies) with specific primers for mouse: Cacna2d1 (Mm00486607_m1), Cacna2d2 (Mm00457825_m1), Cacna1a (Mm00432190_m1), Cacna1b (Mm01333678_m1), Cacna1c (Mm01188822_m1), Cacna1d (Mm01209927_g1), Cacna1e (Mm00494444_m1), Cacna1f (Mm01352612_ m1), Cacna1s (Mm00489257_m1), Icam1 (Mm00516023_m1), Vcam1 (Mm01320970_m1), Claudin (Mm01320970_m1), Zo-1 (Mm00493699_m1) and eukaryotic 18S ribosomal RNA (18S rRNA) as endogenous control (VIC/MGB probe; 4319413E). Relative expression was calculated using $2^{\wedge}-\Delta \Delta \mathrm{Ct}[34$, 35].

Viability assay

Splenocytes were isolated as described before and cultured for 2 days and stimulated with CD3/CD28 beads (cell to bead ratio: 2:1; \#111.61D, Gibco ${ }^{\mathrm{TM}}$ Dynabeads $^{\mathrm{TM}}$ Human T-Activator CD3/CD28, Thermo Fisher Scientific) or left unstimulated. Splenocytes were cultivated with different concentrations of pregabalin and stained with fixable viability dye eFluor 780 (\#65-0865-14, Affimetrix Biosciences, Santa Clara, CA) before measuring them using flow cytometry.

\section{$\mathrm{Ca}^{2+}$ imaging}

For $\mathrm{Ca}^{2+}$ imaging experiments, splenocytes were isolated as described above. Analysis was performed in HEPES buffer containing $120 \mathrm{mM} \mathrm{NaCl}, 2.5 \mathrm{mM} \mathrm{KCl}, 125 \mathrm{mM} \mathrm{NaH}_{2} \mathrm{PO}_{4}, 30 \mathrm{mM}$ HEPES, $2 \mathrm{mM} \mathrm{MgSO}{ }_{4}$, $10 \mathrm{mM}$ glucose, $\mathrm{pH} 7.25$ and osmolality set to $305 \mathrm{mOsm}^{*} \mathrm{~kg}^{-1}$. Cells were loaded with $5 \mu \mathrm{M}$ Fura-2 AM (Invitrogen, Karlsruhe, Germany) for 30 minutes at $37^{\circ} \mathrm{C}$. Fluorescence was measured with a TECAN infinite M200Pro fluorimeter (Tecan Group Ltd., Männerdorf, Switzerland). Excitation was alternated between 340 and $380 \mathrm{~nm}$, and emission was measured at $509 \mathrm{~nm}$ every 3 seconds [36]. 


\section{Primary murine microglia culture}

Mouse pups (postnatal days 1-5) were decapitated and after removal of the cerebellum the meninges were extracted. Up to 5 brains were homogenized together in $5 \mathrm{ml} \mathrm{L-glutamine-containing} \mathrm{DMEM}$ supplemented with $10 \%$ FCS, $1 \%$ NEAAs, $1 \%$ antibiotics and $0.1 \% \beta$-mercaptoethanol. The supernatants were incubated for 5 minutes on ice and after centrifugation of the pooled supernatants at $486 \mathrm{xg}$ for 5 minutes at room temperature the pellets were resuspended in $1 \mathrm{ml}$ medium/2-3 brains. The cell suspensions were transferred to Poly-L-lysine (Sigma-Aldrich) pre-coated $75 \mathrm{~m}^{2}$ cell culture flasks in a total volume of 10 $\mathrm{ml}$ each and incubated at $37{ }^{\circ} \mathrm{C}$ and $5 \% \mathrm{CO}_{2}$. After 1 and 7 days of culturing the medium was changed. After 7 additional days of culturing, microglial cells were selectively detached by carefully knocking against the flask. Suspended microglia cells were pelleted at $300 \mathrm{x}$ g for 5 minutes at room temperature, before being seeded. After resting for 1 day the primary microglia cells were either left untreated or treated with either $500 \mu \mathrm{g}^{*} \mathrm{ml}^{-1}$ pregabalin or $100 \mathrm{U}^{*} \mathrm{ml}^{-1} \mathrm{IFN}-\gamma$, or a combination of both treatments. After incubation for 1 day, cells were washed with FACS buffer (0.1\% BSA, $0.01 \%$ sodium azide and 2.53 mM EDTA in PBS) and stained for 30 minutes with MHCII-PE (clone M5/114.15.2, BD Pharmingen), CD86-PE-Cy7 (clone GL-1, Biolegend), and CD40-APC (clone IC10, eBioscience) as activation markers, FVD780 as a live cell marker, and CD11b-PB (clone M1/70, Biolegend) and CD45-BV510 (clone 30-F11, Biolegend) to distinguish microglia cells from astrocytes in flow cytometry. Some of the cells were collected for rRT-PCR.

\section{Primary mouse brain endothelial cells and TEER measurements}

Primary mouse brain microvascular endothelial cells (MBMECs) were prepared from brains of naïve mice as described earlier [32, 37] and cultured for 6 days before they were reseeded on Collagen IV/ fibronectin (Sigma)- coated Transwell inserts with a $0.4 \mu \mathrm{m}$ pore polyester membrane in a density of $2 \times 10^{4}$ cells/well (Corning, Lowell, MA, USA). Purity, confluence and cell morphology were checked on a regular basis using flow cytometry, resistance measurements and microscopy. To assess the effects of pregabalin on MBMECs, the cells were treated with pregabalin $\left(500 \mathrm{\mu g}^{*} \mathrm{ml}^{-1}\right)$ after reseeding and the transendothelial electrical resistance was monitored with the cellZscope apparatus (nanoAnalytics GmbH, Münster, Germany). When the cells reached a resistance plateau they were either kept naïve or inflamed with IFN- $\gamma$ and TNF- $\alpha$ (each $500 \mathrm{U}^{*} \mathrm{ml}^{-1}$ ) for 24 hours. Twenty-four hours post inflammation, MBMECs were collected and the RNA was isolated to proceed with rRT-PCR experiments as described before with the indicated Taqman primers.

\section{Slice preparation for LTP measurements}

The brain was removed under deep isoflurane anesthesia and was transferred to $4{ }^{\circ} \mathrm{C}$ artificial cerebrospinal fluid (ACSF). The ACSF was equilibrated with $5 \% \mathrm{CO}_{2}$ and $95 \% \mathrm{O}_{2}$. After removing the cerebellum and dividing the two cerebral hemispheres, the brain was cut in a horizontal plane $(500 \mu \mathrm{m})$ with a vibroslicer (Campden Instruments, USA). The composition of ACSF was (in mmol*l-1): $\mathrm{NaCl}, 124$; $\mathrm{KCl}, 4 ; \mathrm{CaCl}_{2}, 1.0 ; \mathrm{NaH}_{2} \mathrm{PO}_{4}, 1.24 ; \mathrm{MgSO}_{4}, 1.3 ; \mathrm{NaHCO}_{3}, 26$; and glucose, 10 (pH 7.4). After 30 minutes of incubation, $\mathrm{Ca}^{2+}$ concentration of ACSF was increased to $2.0 \mathrm{mM}$. Slices were individually transferred to an interface recording chamber, placed on a transparent membrane, illuminated from above and continuously perfused $\left(1.5-2 \mathrm{ml}^{*} \mathrm{~min}^{-1}\right)$ with gassed ACSF at $32^{\circ} \mathrm{C}$. A warmed and humidified gas mixture of $95 \% \mathrm{O}_{2}$ and $5 \% \mathrm{CO}_{2}$ was evaporated over the slices.

\section{Electrophysiological recordings}

Extracellular field potentials were recorded with glass microelectrodes $\left(150 \mathrm{mmol}^{*} \mathrm{l}^{-1} \mathrm{NaCl} ; 2-5\right.$ $\mathrm{M} \Omega$ ) in the hippocampal CA1 area. The reference electrode and the connection to the microelectrode were symmetric silver-silver-KCl bridges. Evoked field potentials were induced by single pulses of electrical stimulation applied through a bipolar platinum electrode attached to the hippocampal Schaffer collaterals in slices of control $(n=9)$ or pregabalin-treated $\left(n=10 ; 30 \mathrm{mg}^{*} \mathrm{~kg}^{-1}\right)$ mice. Stimulation intensity was reduced to bring the field excitatory postsynaptic potential (fEPSP) amplitude to approximately $50 \%$ of the maximum amplitude. The Schaffer collaterals were repeatedly stimulated once every minute. The fEPSP amplitude was stable (maximum deviation of $10 \%$ ) for at least 20 minutes before induction of long-term potentiation (LTP). The tetanic stimulation consisted of a $100 \mathrm{~ms}$ long train of $100-\mathrm{Hz}$ electrical pulses and the duration of an electrical pulse was $0.1 \mathrm{~ms}$ with an inter-pulse interval of $10 \mathrm{~ms}$. Four trains were 
delivered to the Schaffer collaterals with a train interval of $100 \mathrm{~ms}$. LTP was described as the mean changes in fEPSP amplitude in response to five stimuli delivered 30 minutes after LTP induction compared to the mean response to five pulses given immediately before tetanic stimulation. The fEPSP amplitude was measured from the most positive to the most negative deflection. fEPSP recordings were continued for 60 minutes after induction of LTP. fEPSP recordings were monitored and analyzed using WinLTP software (The University of Bristol, UK) [38].

\section{Intravital two photon imaging in passive EAE animals}

Naïve $\mathrm{CD}^{+}{ }^{+} \mathrm{CD} 62 \mathrm{~L}^{+}$cells were isolated and MACS-sorted from spleens and lymph nodes of B6.IL17A. RFPacGFP mice (6-10 weeks old) with a purity of $>95 \%$ of total cells. Interleukin (IL)-17A-producing effector T-helper $\left(\mathrm{T}_{\mathrm{H}} 17\right)$ cell differentiation was achieved by adding $2 \mu^{*} \mathrm{ml}^{-1}$ anti-CD3 (clone 145-2C11; eBioscience), 3 ng* ml $^{-1}$ TGF- $\beta$ (R\&D, USA), 20 ng*ml $^{-1}$ mrIL-6 (R\&D, USA), 20 ng*ml $^{-1}$ IL-23 (R\&D, USA), $10 \mathrm{\mu g}^{*} \mathrm{ml}^{-1}$ anti-IL-4 (11B11, BioXCell, USA) and $10 \mu \mathrm{g}^{*} \mathrm{ml}^{-1}$ anti-IFN- $\gamma$ (XMG1.2, BioXCell, USA). Irradiated antigen presenting cells (APCs) were used for initial stimulation of the T lymphocytes at a ratio of 1:10. Cells were kept in DMEM media containing $10 \mathrm{mM}$ HEPES (H4034 Sigma-Aldrich), $25 \mu^{*} \mathrm{ml}^{-1}$ gentamicin (\#15750-060, Gibco), 5 \% FBS (ScienCell), 2 mM glutamine (Gibco) and $1 \%$ non-essential amino acids (NNEAs, \# M7145, Sigma-Aldrich) and were split with $50 \mathrm{U}^{*} \mathrm{ml}^{-1} \mathrm{IL}-2$ (R\&D, USA) and $10 \mathrm{ng}^{*} \mathrm{ml}^{-1} \mathrm{IL}^{-23}$. After seven days in culture cells were re-stimulated with fresh APCs. T cells were generally extracted for transfer on day 10 and showed IL-17A production of $>30 \%$. Next, passive EAE in C57BL/6J.Thy1-TN-XXLxRag2gc ${ }^{-/}$ mice was induced by the transfer of $1 \times 10^{7} \mathrm{CD} 4^{+} \mathrm{T}_{\mathrm{H}} 17$ cells (B6.IL17A.RFPacGFP) intravenously. Utilizing this approach, we took advantage of the intrinsic expression of the reporter mice for the calcium fluorescent probe TN-XXL (525 nm/YFP) and the possibility of identifying immune cells with the RFP/GFP tags. The clinical course of EAE was monitored daily using the following score system: grade 0, no detectable signs; grade 1, complete tail paralysis; grade 2, partial hind limb paralysis; grade 3, complete bilateral hind limb paralysis; grade 4, total paralysis of forelimbs and hind limbs and grade 5, death. Animals with a score $>4$ were excluded from the experiment and the last score observed was included in the analysis until the end of the experiment. In two separate experiments, intravital two-photon microscopy was performed in the brain stem of living anaesthetized mice at a disease score of 2-2.5. In the first experiment (acute treatment group), pregabalin $\left(6 \mu \mathrm{g}^{*} \mathrm{ml}^{-1}\right)$ was perfused locally and cells were imaged after 30 minutes. In the second experiment (chronic treatment group), mice were pretreated with pregabalin (30 $\mathrm{mg}^{*} \mathrm{~kg}^{-1} \mathrm{BW}$ ) intraperitoneally for 3 days twice a day until they reached a score of 2 . Results are visualized in a false color code: immune cells as well as somata/axons are labelled in red (RFP) and yellow/blue (TN-XXL = YFP, CFP), respectively. Neuronal free $\mathrm{Ca}^{2+}$ levels were assessed by FRET measurements and results are presented as the ratio calculated between the fluorescence intensity measured at $525 \mathrm{~nm}$ (YFP) and $475 \mathrm{~nm}$ (GFP) (intensity modulated ratio, IMR). Quantification of intraaxonal and intrasomal free $\mathrm{Ca}^{2+}$ levels of the whole neuronal population over time was calculated via the IMR using the software Volocity (Improvision, Forchheim, Germany).

\section{Experimental Design and Statistics}

All results are presented as mean \pm S.E.M. We performed statistical analysis using Student's $t$ test or Mann-Whitney U-test for parametric or non-parametric data, respectively. We applied two-way analysis of variance (ANOVA) with Bonferroni post hoc for the analysis of the EAE experiments. In the case of multiple comparisons, one-way ANOVA was followed by post hoc analysis using Newman-Keuls multiple comparisons test or Kruskal Wallis test with Dunn post hoc analysis. Data were analyzed and plotted using Prism 5.03 (Graph Pad, USA). Differences were considered statistically significant if $p<0.05$. The level of significance was labelled according to the $p$ values $\left({ }^{*} p<0.05,{ }^{* *} p<0.01\right.$ or $\left.{ }^{* * *} p<0.001\right)$. The n number of each experiment is given in the text.

\section{Results}

Pregabalin ameliorates the course of EAE

To assess whether pregabalin treatment affects clinical symptoms of EAE, we immunized three different groups of C57BL/6J mice with $\mathrm{MOG}_{35-55}$ peptide and evaluated clinical scores 
Fig. 1. Pregabalin treatment ameliorates active EAE course. A. Female C57BL/6J mice were immunized with $200 \mu \mathrm{g}$ myelin oligodendrocytic glycoprotein $\left(\mathrm{MOG}_{35-55}\right)$ peptide in complete Freund's adjuvant (CFA). Mice were treated with pregabalin (30 mg* $\mathrm{kg}^{-1}$ BW, daily; $100 \mu \mathrm{l}$ i.p. once daily) or vehicle (Ctrl, $0.9 \%$ $\mathrm{NaCl}$ ) starting from the day of immunization (Preg (prophylactic) or when animals showed first clinical disease signs $\left(\mathrm{d}_{\max }\right)$ (Preg (therapeutic), respectively. Clinical symptoms were evaluated daily using an EAE score from 1 to 10 (left). Mean cumulative scores of Ctrl, Preg (prophylactic) and Preg (therapeutic) are shown (right). B-C. Inflammatory and demyelinated areas were quantified by HE and LFB staining, respectively, in spinal cord sections at $\mathrm{d}_{\max }$ from Ctrl and Preg (prophylactic) treated mice (B) and at $d_{\text {end }}$ from Preg (prophylactic) and Preg

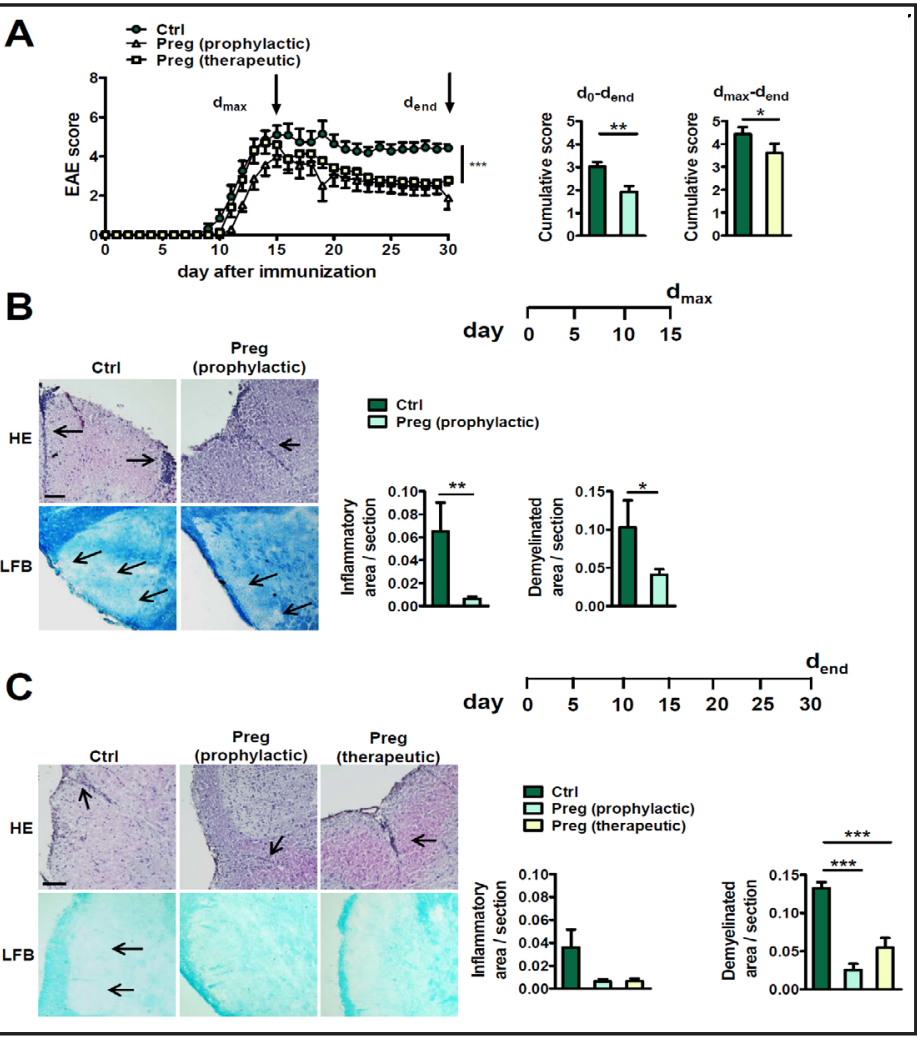
(therapeutic) treated as well as Ctrl mice (C). Representative sections of each group are shown on the left side. Arrows indicate inflammation or demyelinated areas, respectively

daily over a period of 30 days. Pregabalin was administered intraperitoneally (daily, 30 $\mathrm{mg}^{*} \mathrm{~kg}^{-1} \mathrm{BW}$ according to the daily maximum dose for humans) either starting from day 1 (prophylactic treatment; Preg (prophylactic)) or from the day of disease maximum (day 15, $d_{\text {max }}$, therapeutic treatment; Preg (therapeutic) ) until the end of the experiment $\left(d_{\text {end }}\right)$. The control group (Ctrl) was treated with a vehicle $(0.9 \% \mathrm{NaCl})$ throughout the experiment. Prophylactic treatment resulted in a delayed disease onset and reduced disease severity at $\mathrm{d}_{\max }$ compared to the non-treated control animals (Two Way ANOVA $\mathrm{F}_{(2,1367)}=71.01$, $\mathrm{p}<0.0001$, Ctrl $\mathrm{n}=20$ vs. Preg (prophylactic) $\mathrm{n}=24$ ) and an ameliorated disease course throughout the whole observation period of 30 days (Fig. 1A). Therapeutic treatment, starting when the mice showed the most severe clinical symptoms of the disease, still resulted in an amelioration of the disease score Preg (therapeutic) $n=18$ vs. Ctrl $(n=20)$ (Fig. 1A). The histological evaluation of mice was done both at $d_{\max }$ and $d_{\text {end }}$ of EAE. Compared to control animals, mice prophylactically treated with pregabalin showed both a significantly reduced area of inflammatory infiltrates (Mann Whitney Test, $p=0.0081$, Ctrl $n=4$ vs. Preg (prophylactic) $\mathrm{n}=8$ ) and less myelin loss as assessed by LFB staining (Mann Whitney Test, $p=0.0283$, Ctrl $n=4$ vs. Preg (therapeutic) n=8) (Fig. 1B). In line with reduced clinical scores in the pregabalin-treated groups, histological analyses at $\mathrm{d}_{\text {end }}$ also revealed a reduction of local CNS inflammation (One Way ANOVA F ${ }_{(2,18)}=3.658, p=0.0492$, Ctrl $n=6$ vs. Preg (prophylactic) $n=7$ vs. Preg (therapeutic) $n=6$ ) and demyelination in the brain (Fig. 1C). In this regard, pregabalin appears to have an impact on disease severity by reducing inflammation and demyelination in the CNS of EAE mice.

To further evaluate the number and phenotype of CNS-invading immune cells, cells from the spinal cord of non-treated (Ctrl) and prophylactically treated animals (Preg (prophylactic)) were isolated and stained with fluorescently labelled antibodies for flow 
Fig. 2. Pregabalin treatment reduces immune cell infiltration into the spinal cord of EAE mice but does not affect responses of $\mathrm{MOG}_{35-55}$-reactive immune cells ex vivo. Aa. Ba. Flow cytometric quantification of CNS-infiltrated cells of Ctrl (green) and pregabalin treatment groups (prophylactic: light green, therapeutic: yellow) at $\mathrm{d}_{\max }(\mathrm{Aa})$ and at $\mathrm{d}_{\text {end }}(\mathrm{Ba})$ are shown. Cell surface staining for CD45 allowed assessing the amount of peripheral infiltration into the CNS. Thus, the number of CD $45^{\text {high }}$ cells is shown. Brain-infiltrating leukocytes were further analyzed for the numbers of $\mathrm{CD}^{2} 5^{\text {high }} \mathrm{CD} 11 \mathrm{~b}^{-}$(identifying peripheral lymphocytes), CD45 $5^{\text {high- }}$ $\mathrm{CD}_{11} \mathrm{~b}^{+}$(identifying peripheral macrophages and dendritic cells), and $\mathrm{CD} 45^{\text {low }} \mathrm{CD} 11 \mathrm{~b}^{+}$(identifying microglia) cells. In a second step, brain-infiltrating lymphocytes $\left(\mathrm{CD} 45^{\text {high }} \mathrm{CD} 11 \mathrm{~b}^{-)}\right.$were further analyzed for the numbers of CD4 $4^{+}$,

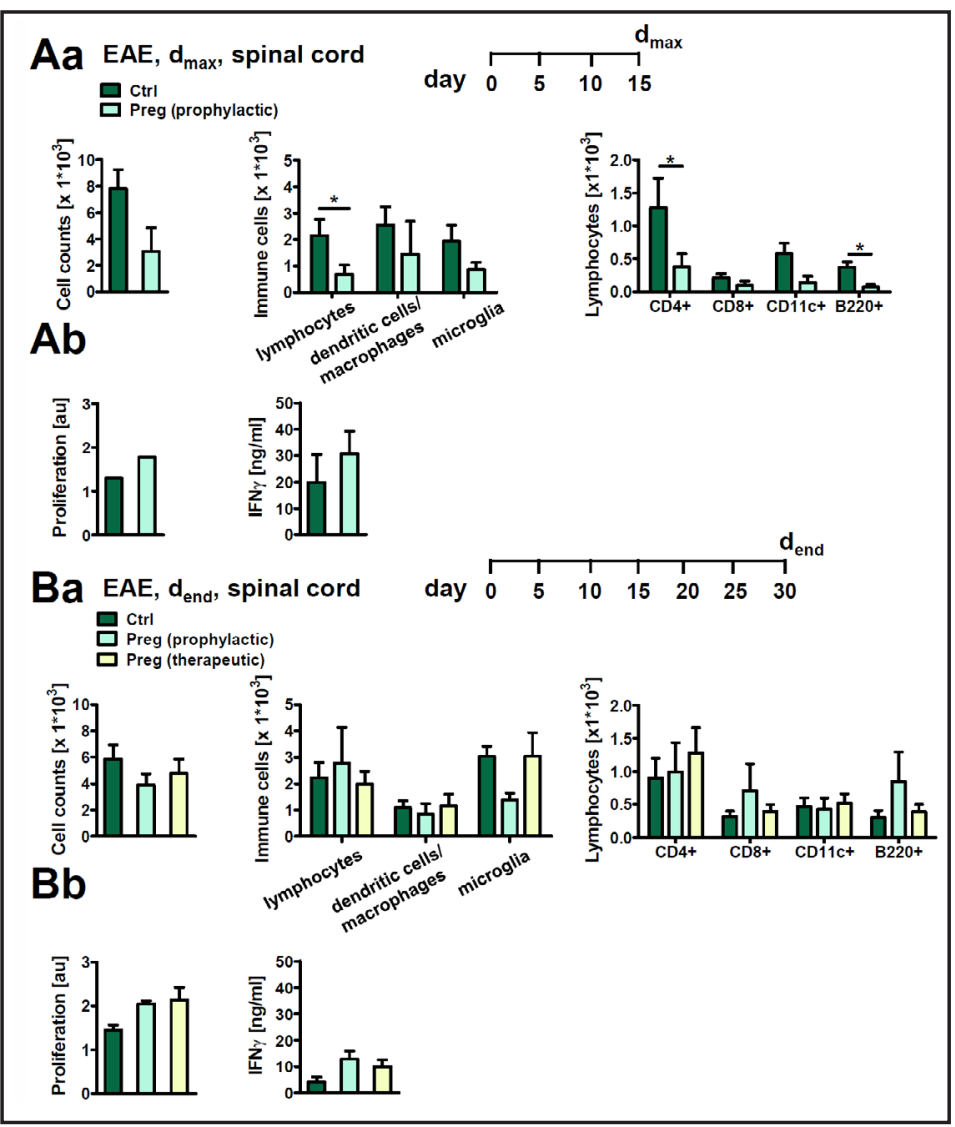

$\mathrm{CD}^{+}, \mathrm{CD} 11 \mathrm{c}^{+}$, and B cells (B220 $)$. Ab. Bb. Proliferative capacity and IFN- $\gamma$ production of splenocytes of Ctrl (green) and pregabalin treated groups at $d_{\max }(A b)$ and at $d_{\text {end }}(B b)$ are shown upon restimulation with 10 $\mu \mathrm{g}^{*} \mathrm{ml}^{-1} \mathrm{MOG}$ peptide for 2 days.

cytometric analyses. The data revealed a reduction of CNS-infiltrated immune cell numbers in prophylactically treated mice at $\mathrm{d}_{\max }$ (Unpaired Student's $t$-test, $\mathrm{t}=2.084, \mathrm{df}=7, \mathrm{p}=0.0756$, Ctrl $n=5$ vs. Preg (prophylactic) $n=4$ ) (Fig. 2Aa, left). More detailed analyses revealed a significant reduction of lymphocytes (Unpaired Student's t-test, $t=2.838, d f=7, p=0.0251, C \operatorname{trl} n=5$ vs. Preg (prophylactic) $n=4$ ) (Fig. 2Aa, middle), more precisely CD4 ${ }^{+} \mathrm{T}$ cells (Unpaired Student's t-test, $\mathrm{t}=2.514, \mathrm{df}=7, \mathrm{p}=0.0402$, Ctrl $\mathrm{n}=5$ vs. Preg (prophylactic) $\mathrm{n}=4$ ) and also CD45R/B220 ${ }^{+}$ $B$ cells (Unpaired Student's t-test, $t=2.911, \mathrm{df}=7, \mathrm{p}=0.0226$, Ctrl $\mathrm{n}=5$ vs. Preg (prophylactic) $\mathrm{n}=4$ ) (Fig. 2Aa, right). To test immune cell effector functions after presentation of the antigen ex vivo, splenocytes were isolated from Ctrl and prophylactically pregabalin treated EAE mice at $\mathrm{d}_{\max }$ and restimulated with MOG peptide $\left(10 \mu \mathrm{g}^{*} \mathrm{ml}^{-1}\right)$. Splenocyte proliferation and production of IFN- $\gamma$ were measured after two days and found to be indifferent between groups (Fig. 2Ab). At $\mathrm{d}_{\text {end }}$, we observed a lower number of CNS-infiltrating immune cells in the control group as compared to $\mathrm{d}_{\text {max }}$. However, there were no differences between the prophylactic and therapeutic treatment groups at $\mathrm{d}_{\text {end }}$, neither concerning the total immune cell counts (Fig. 2Ba left) nor regarding the composition of different immune cell subtypes (Fig. 2Ba middle, right). Moreover, we did not observe any difference between the groups regarding proliferation and IFN- $\gamma$ cytokine production at $\mathrm{d}_{\text {end }}$ after 2 days of restimulation with MOG as cognate antigen in cell culture (Fig. 2Bb). Our data show that prophylactic as well as therapeutic pregabalin treatment significantly lowers disease severity by reducing the number of CNS-infiltrating immune cells. However, pregabalin does not seem to affect the composition or function of immune cells in EAE mice and ex vivo. 
Fig. 3. Other EAE/MS-relevant cell types show no response to pregabalin treatment in vitro. A. Cacna2d1 and Cacna2d2 mRNA expression in murine splenocytes isolated from naïve C57BL/6J mice and stimulated with or without anti-CD3 and anti-CD28 antibodies to induce $\mathrm{T}$ cell receptor stimulation for 48 hours in culture. Real-time reverse transcription-PCR was performed using $18 \mathrm{~S}$ rRNA as endogenous control. B. Murine splenocytes were isolated and stained with efluor670, cultured for 4 days with pregabalin or without pregabalin (Ctrl) and thereafter the proliferation was assessed by flow cytometry C. $\mathrm{Ca}^{2+}$ imaging experiments using Fura-2 in control and pregabalin treated splenocytes were performed (left) and quantified (right). Cross-linked anti-CD3 antibodies for $\mathrm{T}$ cell receptor stimulation (CD3 X-link) were added as indicated by the arrow. D. (left): Cacna2d1 and Cacna2d2 expression in murine microglia after 24 hours' stimulation with $100 \mathrm{U}^{*} \mathrm{ml}^{-1}$

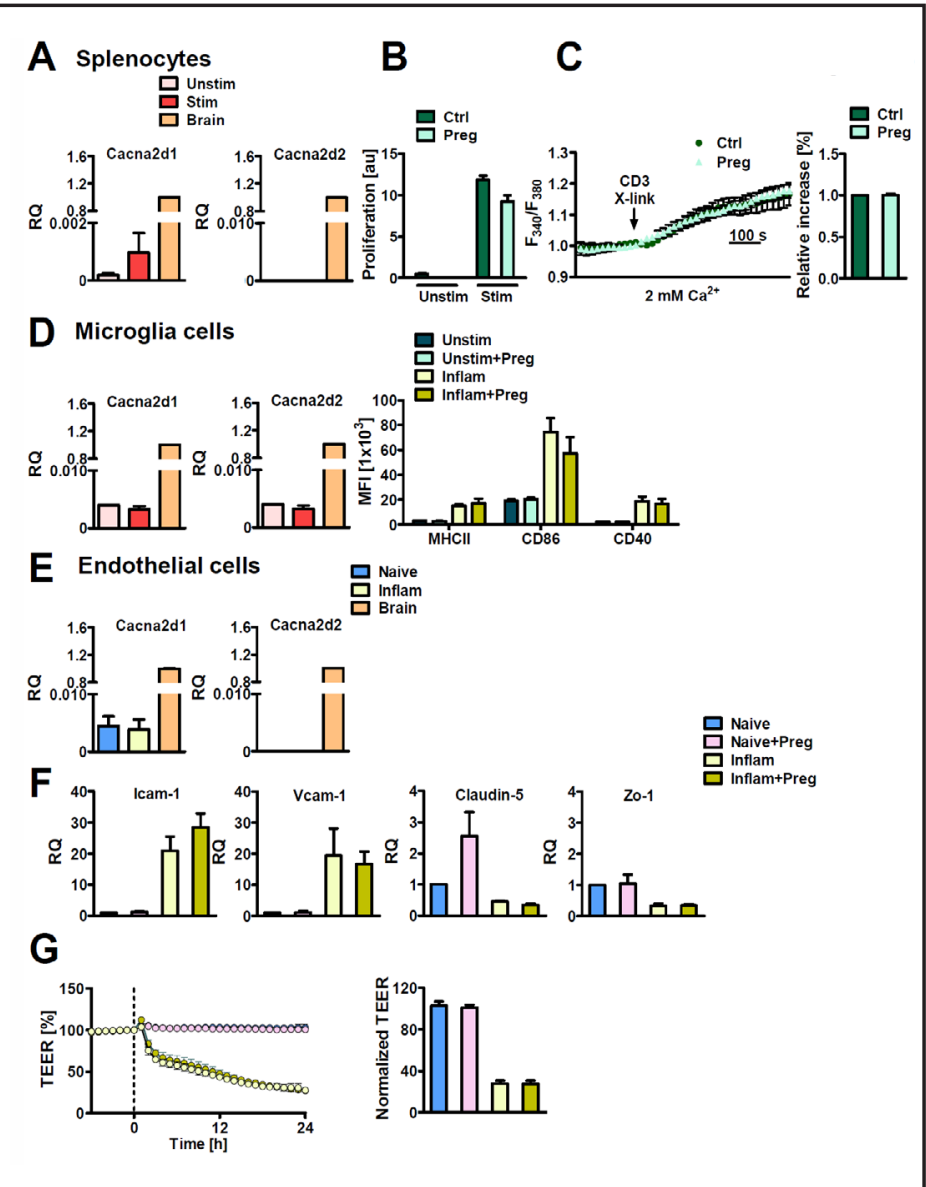

IFN- $\gamma$ and without stimulation determined by rRT-PCR using $18 \mathrm{~S}$ rRNA for normalization (right): Unstimulated and inflamed microglia cultures were analyzed for the expression of MHC-II, CD86 and CD40 by flow cytometry with and without pregabalin. E. rRT-PCR analyses for Cacna2d1 and Cacna2d2 auxiliary subunits in primary mouse brain endothelial cells under naïve and inflammatory conditions. F. rRT-PCR analyses for the adhesion molecules Icam-1, Vcam-1 and the tight junction proteins Claudin- 5 and Zo- 1 and their expression in MBMECs under naïve and inflammatory conditions. G. TEER-measurement of the integrity of a monolayer of murine brain endothelial cells of naïve and inflamed cells with and without pregabalin over $24 \mathrm{~h}$.

Diverse cell types relevant in EAE show no response to pregabalin in vitro

In MS pathophysiology, autoreactive myelin-specific T cells are generated in the periphery, circulate with the blood flow and enter the CNS initiating a chronic inflammatory response in the brain. However, besides peripheral immune cells, brain endothelial cells of the blood-brain-barrier (BBB) as well as CNS-resident microglia contribute to inflammation and axonal damage [39]. As it is known that $\alpha_{2} \delta$ auxiliary subunits are widely expressed [40], we systemically checked the mRNA expression of the pregabalin-sensitive $\alpha_{2} \delta$ auxiliary subunits, $\alpha_{2} \delta-1$ (gene: Cacna2d1) and $\alpha_{2} \delta-2$ (gene: Cacna2d2), as well as functional pregabalin effects in different cell types known to be relevant in MS/EAE pathophysiology.

We first checked on splenocytes isolated from naïve mice for the expression of the pregabalin-sensitive auxiliary subunits, $\alpha 2 \delta-1$ and $\alpha 2 \delta$-2, via rRT-PCR. We found that Cacna2d1 but not Cacna2d2 mRNA is expressed in splenocytes after 48 hours in culture if either left unstimulated or after $\mathrm{T}$ cell receptor stimulation ( $\mathrm{n}=6$ per group). (Fig. 3A). Next, we addressed functional effects of pregabalin administration on immune cell functions. To determine the suitable concentration for pregabalin to be used in vitro, we 
titrated the drug and performed a cell viability assay with splenocytes. We incubated cells with five different pregabalin concentrations $\left(50-5,000 \mu \mathrm{g}^{*} \mathrm{ml}^{-1}\right)$ for at least 48 hours. Up to $500 \mathrm{\mu g}^{*} \mathrm{ml}^{-1}$ application of pregabalin to the cells had no effect on their general viability $(\mathrm{n}=3$ ) (for all online suppl. material, see www.karger.com/doi/ 10.1159/000495425, Suppl. Fig. 1). Accordingly, we applied $500 \mu^{*} \mathrm{ml}^{-1}$ of pregabalin to the naïve splenocytes and saw no significant differences in proliferation between Ctrl and pregabalin treated cells of unstimulated and stimulated splenocytes ( $\mathrm{n}=6$ per group) (Fig. 3B). Additionally, $\mathrm{Ca}^{2+}$ imaging measurements using the $\mathrm{Ca}^{2+}$-sensitive dye Fura-2 were performed and the cells were treated with cross-linked anti-CD3 antibodies (CD3 X-link) to trigger T-cell receptor stimulation. We found no impact of pregabalin in intracellular $\mathrm{Ca}^{2+}$ levels on splenocytes before and after $\mathrm{T}$ cell stimulation ( $\mathrm{n}=6$ per group) (Fig. 3C). Together with the results obtained from the EAE experiments, these experiments suggest that a major impact of pregabalin on lymphocytes is unlikely.

Next, we examined possible pregabalin effects on CNS-resident microglia. Although the mRNAs of both channel subunit isoforms were found to be expressed in microglia cells, the flow cytometric analyses of activation marker expression revealed no substantial effect of pregabalin treatment, neither in unstimulated cells nor in cells inflamed with IFN- $\gamma(500$ $\mathrm{U}^{*} \mathrm{ml}^{-1}$ ) (Fig. 3D). Based on these results, there seems to be no substantial effect of pregabalin on microglia ( $n=3$ per group). Finally, we checked whether pregabalin might affect barrier functions of primary mouse brain microvascular endothelial cells (MBMECs) inflamed with IFN- $\gamma\left(500 \mathrm{U}^{*} \mathrm{ml}^{-1}\right)$ and TNF- $\alpha\left(500 \mathrm{U}^{*} \mathrm{ml}^{-1}\right)$ compared to naïve cells. While the $\alpha 2 \delta-1$ subunit was expressed both in naive and inflamed cells, $\alpha_{2} \delta-2$ was not found to be expressed on mRNA level ( $\mathrm{n}=5$ ) (Fig. 3E). The BBB is composed of specialized brain endothelial cells that are characterized by adhesion molecules and tight junctions which restrict the trafficking of solutes and cells to the CNS. Under inflammatory conditions, the integrity of the BBB is affected through the upregulation of adhesion and the downregulation of tight junction molecules, becoming more permeable to substances from the bloodstream [41, 42]. Here, we examined the pregabalin effects on the BBB integrity by analyzing the expression of the adhesion molecules Icam-1 and Vcam-1 as well as the primary tight junction (TJ) proteins, Zo-1 and Claudin-5 ( $\mathrm{n}=5$ ) (Fig. 3F). In addition, we measured the transendothelial electrical resistance (TEER) across the cellular monolayer (Fig. 3G). Both the expression of the adhesion molecules and tight junction proteins as well as the TEER values were unaltered upon pregabalin treatment, demonstrating that pregabalin does not have an essential effect on the integrity and permeability of the BBB. Our results demonstrate, that endothelial cells show no functional response to pregabalin administration $(n=3)$.

\section{Pregabalin treatment reduces hippocampal LTP}

In order to investigate the effects of pregabalin on essential neuronal mechanisms sustaining higher brain functions related to $\mathrm{Ca}^{2+}$ influx, such as learning and memory, electrophysiological LTP measurements were conducted in acute brain slices obtained from mice pre-treated either with pregabalin $\left(30 \mathrm{mg}^{*} \mathrm{~kg}^{-1} \mathrm{BW}\right)$ or vehicle for 3 days. After $30 \mathrm{~min}$ of stable recording a conditioning high-frequency electrical stimulation (tetanus) was delivered to the Schaffer collateral of hippocampal slices at $t=0$ (as indicated by the arrow Fig. 4A). High frequency electrical stimulation produced a stable and lasting enhancement of the amplitude of fEPSP (as indicated by the exemplary traces, Fig. 4B) in all tested slices of control mice (Fig. 4A). Pregabalin treatment under non-inflammatory conditions significantly reduced LTP induction in the hippocampus in all tested slices (Unpaired Student's t-test, $\mathrm{t}=19.25, \mathrm{df}=17, \mathrm{p}<0.0001$, Ctrl $\mathrm{n}=9$ vs. Preg $\mathrm{n}=10$ ) (Fig. 4C) indicating that this drug influences basal cellular mechanisms of learning and memory in hippocampal neurons. These data confirm the contribution of VGCCs towards LTP and memory formation [43] and the functional impact of pregabalin on central neurons. However, until this date we have received no clinical reports indicating that pregabalin-treated patients have learning deficits or show memory impairments. 


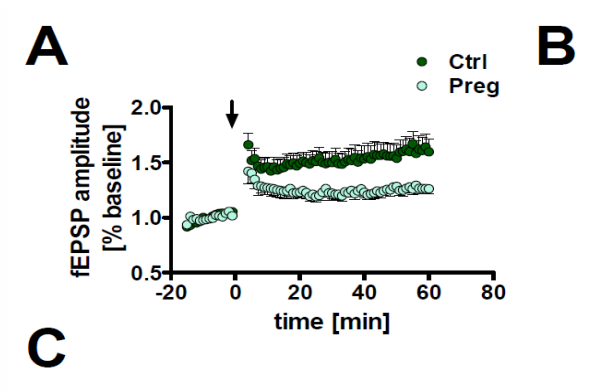

B
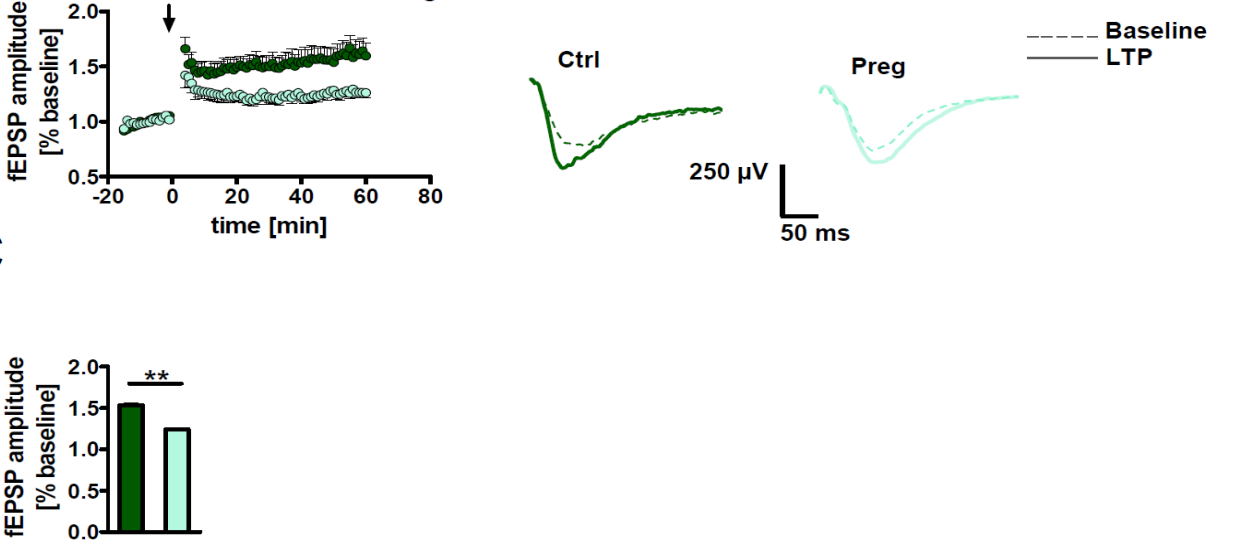

Fig. 4. Long-term potentiation (LTP) of the evoked field excitatory postsynaptic potential (fEPSP) in hippocampal neurons. A. Field excitatory postsynaptic potentials (fEPSP) recorded from hippocampal neurons after stimulation of the Schaffer collaterals in acute living brain slices of mice pretreated with vehicle- (Ctrl) or pregabalin (Preg, $30 \mathrm{mg}^{*} \mathrm{~kg}^{-1} \mathrm{BW}$ pregabalin twice daily for 3 consecutive days prior to the experiment). B. Graph representing the amplitude of fEPSPs in the two experimental mouse groups. C. Representative traces of fEPSP before (baseline) and after the stimulation (LTP) in different groups.

Pregabalin reduces neuronal $\mathrm{Ca}^{2+}$ elevations promoted by CNS infiltrating $C D 4^{+} \mathrm{T}$ cells

IL-17 producing $\mathrm{CD}^{+} \mathrm{T}_{\mathrm{H}} 17$ cells play a pivotal role in EAE and lead to neuronal $\mathrm{Ca}^{2+}$ elevations after CNS infiltration [44]. Neuronal $\mathrm{Ca}^{2+}$ overload is a major decision point of neuronal fate in inflammatory lesions, as neurons can either recover or progress from a vulnerable state to cell death $[44,45]$. As pregabalin is known to reduce neuronal $\mathrm{Ca}^{2+}$ influx and harmful excitotoxicity [12], we investigated the effect of pregabalin on neuronal $\mathrm{Ca}^{2+}$ levels after the infiltration of autoreactive immune cells into the brain of adoptive transfer EAE mice using intravital two-photon microscopy after acute and chronic pregabalin treatment (experimental timeline in Fig. 5A). In agreement with the well-known pregabalin effect mediated via inhibition of the VGCC trafficking, acute pregabalin perfusion $\left(6 \mu \mathrm{g}^{*} \mathrm{ml}^{-1}\right.$ according to serum concentration) did not influence the $\mathrm{Ca}^{2+}$ elevations of intraaxonal or intrasomal $\mathrm{Ca}^{2+}$ (Fig. 5B, C). In a second set of experiments, EAE mice were pretreated with pregabalin intraperitoneally ( $30 \mathrm{mg}^{*} \mathrm{~kg}^{-1} \mathrm{BW}$, for 3 days twice a day) when reaching an EAE score of 2 and were imaged thereafter. This pretreatment led to a significant decrease of intraaxonal and intrasomal $\mathrm{Ca}^{2+}$ levels of the whole neuronal population over time slices (Unpaired Student's t-test, $\mathrm{t}=3.583, \mathrm{df}=8, \mathrm{p}=0.0072$, EAE $\mathrm{n}=5$ vs. EAE+acute $\mathrm{n}=5$; Unpaired Student's t-test, $\mathrm{t}=3.661, \mathrm{df}=8, \mathrm{p}=0.0064$, EAE+acute $\mathrm{n}=5$ vs. EAE+chronic $\mathrm{n}=5$ (Fig. 5B, D). Based on our results, the chronic pregabalin treatment appears to have great potential to provide neuroprotection by preventing $\mathrm{Ca}^{2+}$ mediated excitotoxicity.

\section{Discussion}

A long-lasting increase in neuronal $\mathrm{Ca}^{2+}$ may trigger apoptotic signals and neuronal degeneration, and is a hallmark of different pathophysiological conditions, including inflammatory CNS diseases [44, 46,47$]$. In the development of EAE, $\mathrm{Ca}^{2+}$ influx via VGCCs plays a significant role, and the application of diverse $\mathrm{Ca}^{2+}$ channel inhibitors has been shown to significantly improve the EAE disease course and to postpone the disease onset in treated animals as compared to control animals [48-50]. Furthermore, it has been found that pregabalin ameliorates EAE in rats and reduces synaptic loss and astroglial reaction [51]. However, these studies did not clearly identify pregabalin sensitive cell types nor its mode of action in EAE pathophysiology. 


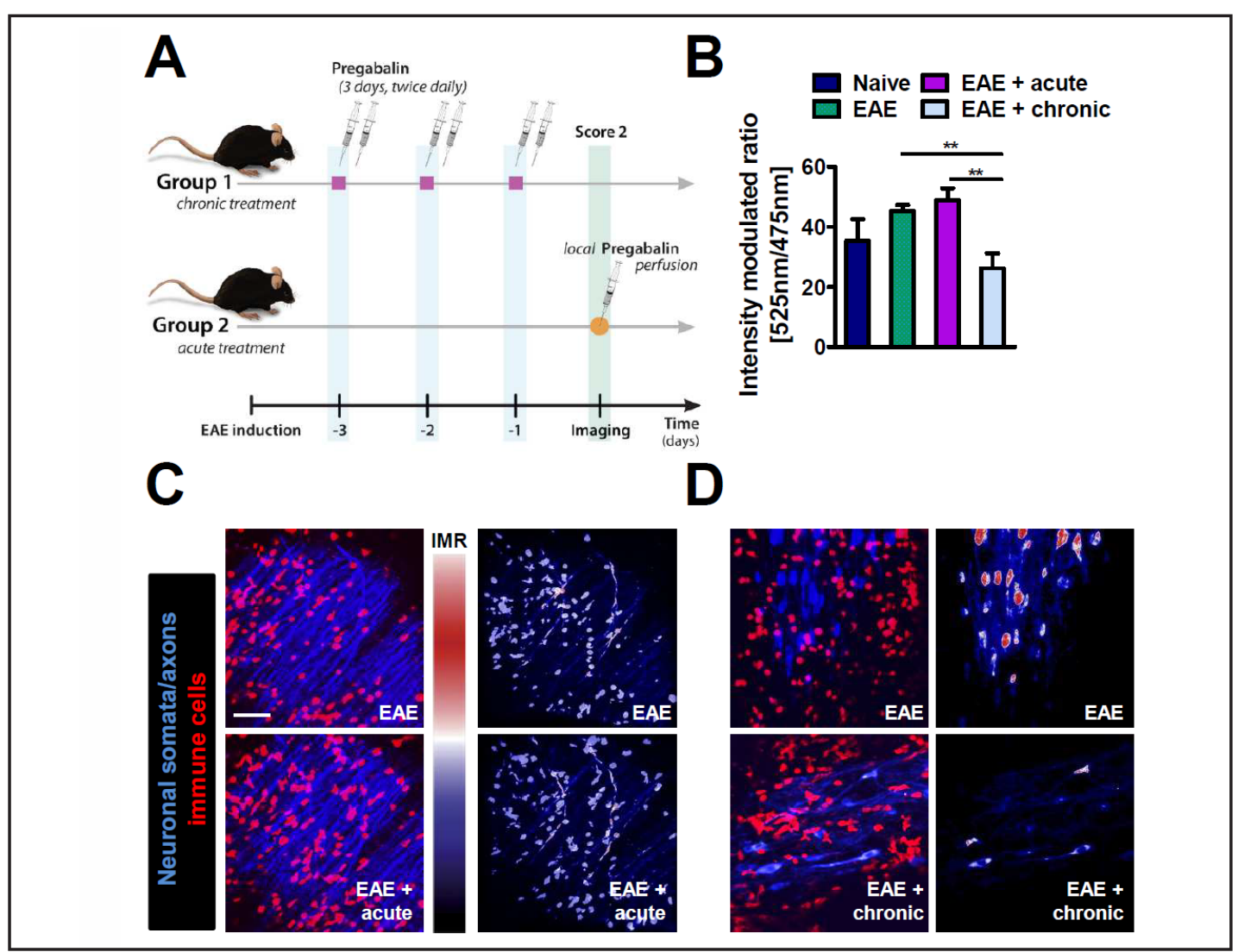

Fig. 5. Intravital imaging reveals a pregabalin-induced reduction in neuronal $\mathrm{Ca}^{2+}$ levels in EAE mice. Passive EAE was induced in C57BL/6J.Thy1-TN-XXLXRag2 $\mathrm{gc}^{-/-}$by transferring $\mathrm{CD}^{+} \mathrm{T}_{\mathrm{H}} 17$ cells intravenously and intravital imaging of intraaxonal and intrasomal free $\mathrm{Ca}^{2+}$ levels were performed when mice reached an EAE score of 2. To note, immune cells (RFP, red) infiltrate the upper brainstem region and show close proximity with somata and axons (blue). Neuronal free calcium levels were assessed by FRET measurements (intensity modulated ratio (IMR) $525 \mathrm{~nm} / 475 \mathrm{~nm}$, false color code representation). A. Schematic representation of the experimental timeline. B. Overall quantification of $\mathrm{Ca}^{2+}$ levels (intensity modulated ratio [525 $\mathrm{nm} / 475$ $\mathrm{nm}]$ ) in naïve mice, untreated EAE mice as well as EAE mice after acute and chronic pregabalin treatment is shown. C. Acute pregabalin treatment $\left(6 \mu \mathrm{g}^{*} \mathrm{ml}^{-1}\right)$ was performed by perfusing the drug locally and thereafter brains were imaged for 30 minutes. Exemplary pictures are shown. D. For chronic treatment, EAE mice were pretreated with pregabalin $\left(30 \mathrm{mg}^{*} \mathrm{~kg}^{-1} \mathrm{BW}\right)$ intraperitoneally for 3 days twice a day when reaching a score of 2 and were imaged thereafter. Exemplary pictures are shown.

Several $\mathrm{Ca}^{2+}$ channels have been implicated in the pathophysiology of neurodegeneration under autoimmune inflammatory conditions [52]. $\mathrm{Ca}^{2+}$ elevation to pathological levels has serious consequences for neuronal survival since several injury mechanisms are activated, e.g. apoptotic signaling pathways through the activation of the $\mathrm{Ca}^{2+}$-dependent proteases calpain and caspases [53], disturbed axonal trafficking through the activation of protease activity [54] and energy deficits through oxidative stress in mitochondria as the main $\mathrm{Ca}^{2+}-$ buffering organelles $[55,56]$. These triggers (oxidative stress, mitochondrial dysfunction, and $\mathrm{Ca}^{2+}$ overload) can lead to abnormalities in glutamate signaling and finally to glutamateinduced excitotoxicity and neurodegeneration [57].

The results of our study demonstrate that prophylactic and therapeutic pregabalin treatment ameliorates the course of EAE, the experimental animal model of MS, by directly and predominantly acting on neurons. As underlying mechanism, it seems that pregabalin reduces harmful $\mathrm{Ca}^{2+}$ elevations promoted by the infiltration of CD4 ${ }^{+} \mathrm{T}$ cells in the CNS. We did not detect a pregabalin mode of action affecting other cell types related to the MS/EAE-patho- 


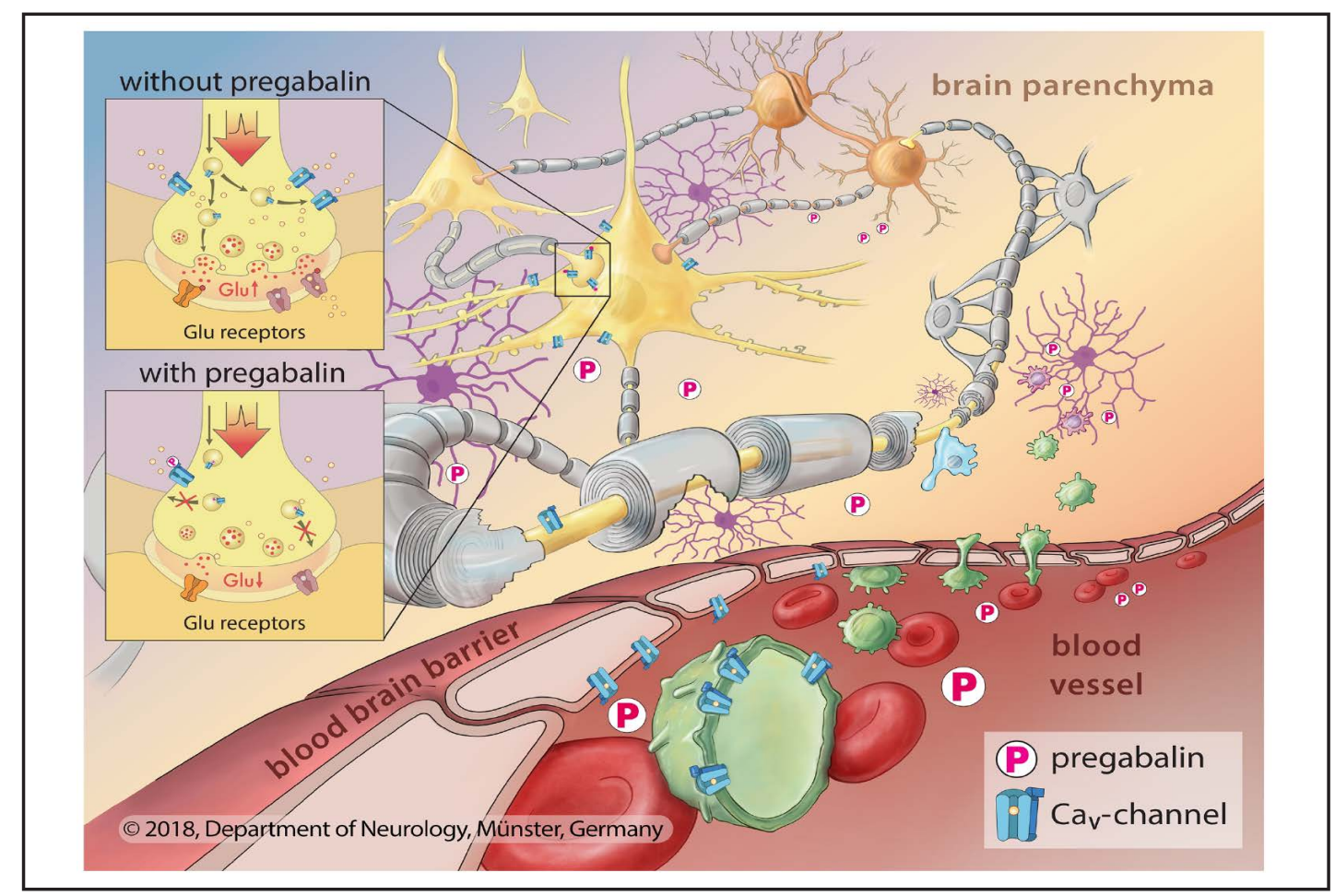

Fig. 6. Pathophysiology of multiple sclerosis and pregabalin-mediated reduction of $\mathrm{Ca}^{2+}$-influx in presynaptic terminals. In lymphoid organs autoreactive T cells interact with antigen-presenting cells and B cells and, after activation, are able to cross the blood-brain barrier. In the CNS, reactivation of autoreactive T cells results in demyelination, axonal injury and neurodegeneration. Pregabalin ameliorates the pathophysiology in an experimental animal model of MS by directly and predominantly acting on neurons. As underlying mechanism, it seems that pregabalin reduces harmful $\mathrm{Ca}^{2+}$ elevations promoted by the infiltration of $\mathrm{CD}^{+}$ $\mathrm{T}$ cells in the CNS while the drug does not affect other cell types related to the MS/EAE-pathophysiology. Red, erythrocytes; green, immune cells; yellow, neurons; violet, microglia; grey, oligodendrocytes/myelin.

physiology, such as naïve and MOG-reactive lymphocytes, CNS-resident microglia, or brain endothelial cells (Fig. 6). These data are in strong support of $\mathrm{Ca}^{2+}$ channels as promising therapeutic targets for the treatment of MS. Since our study reveals pregabalin effects solely in neurons with moderate clinical side effects, we propose a re-purposing of pregabalin for treatment of early stages of neurodegenerative diseases. During the last decade, different drugs have been developed to modify the course of MS, however, there is an unmet need to develop new therapeutic agents to prevent or reverse disease progression and neurological degeneration. Pregabalin is currently administered to treat neuropathic pain, mainly in late stages of MS. The data of our study suggest that pregabalin might also be beneficial in early disease phases preventing neuronal damage due to long-lasting $\mathrm{Ca}^{2+}$ overload. Generally, re-purposing of already approved drugs is an attractive strategy, combining the advantages of successfully passed clinical trials and (especially in terms of pregabalin) long term experience in clinical use. As an example, amiloride, a licensed diuretic, was clinically tested as a neuroprotective agent in MS, blocking acid sensing ion channels. In a clinical phase II trial (ACTION), the neuroprotective efficacy of amiloride in acute optic neuritis, a common manifestation of MS was assessed [58]. While the ACTION trial revealed that amiloride does not protect retinal nerve fiber layer thickness following acute optic neuritis [59], there is an ongoing trial (SMART) on its actions in secondary progressive MS [60,61]. Moreover, there are also trials to re-purpose other already licensed medications, e.g. clemastin fumarate as a remyelinating therapy for multiple sclerosis (ReBUILD) [62] or phenytoin in acute optic neuritis [63]. Our data reveal the potential benefit of expanding the indication for pregabalin 
administration to MS patients far beyond neuropathic pain. Since the drug seems to exert a direct neuroprotective effect, a next step should be the therapeutic evaluation of pregabalin in a clinical trial on early and late multiple sclerosis stages to fully characterize the effects of pregabalin on neuronal survival.

\section{Acknowledgements}

The authors thank Susithira Sasikanthan, Frank Kurth, Monika Wart and Jeannette Budde for their excellent technical assistance. The authors also want to thank Zoë Hunter and Heike Blum for excellent paper revision and graphical illustration, respectively.

\section{Statement of Ethics}

All animal experiments were approved by local authorities and conducted according to German law.

\section{Funding}

This study was supported by the German Research Foundation (excellence cluster EXC 1003 'Cells in Motion' (CiM), EH 469/1-1 (Hundehege), TRR 128/2 2016 TP B05 (Meuth/ Zipp), TRR 128/2 2016 TP B06 (Meuth/Budde/Pape) and TRR 128/2 2016 TP B12 (Bittner) and the Hertie foundation (mylab, Bittner).

\section{Disclosure Statement}

$\mathrm{PH}$ receives speaker honoraria, travel support (Novartis, Merck Serono). Her research is funded by the Deutsche Forschungsgesellschaft (DFG), Interdisciplinary Center for Clinical Studies (IZKF) Muenster, Merck Serono, and Novartis.

TR received travel expenses and financial research support from Genzyme and Novartis and received honoraria for lecturing from Roche, Merck, Genzyme, Biogen, and Teva.

KG declares no competing financial interest. Her research is funded by the Deutsche Forschungsgesellschaft (DFG), Else Kröner Fresenius Foundation and the Medical Faculty Münster.

TB research is funded by the Deutsche Forschungsgesellschaft (DFG), Interdisciplinary Center for Clinical Studies (IZKF) Münster and Biogen.

FZ has received research grants from Genzyme and Merck Serono, as well as consultation funds from Roche, Merck Serono, Novartis, Sanofi- Aventis, Celgene and Octapharma.HW

HW has received honoraria for lecturing, travel expenses for attending meetings and financial research support from Alexion, Biogen, Cognomed, F. Hoffmann-La Roche Ltd., Gemeinnützige Hertie-Stiftung, Merck Serono, Novartis, Roche Pharma AG, Sanofi-Genzyme, TEVA, WebMD Global, Abbvie, Actelion, IGES, Novartis, Roche, Swiss Multiple Sclerosis Society

SB has received consultation funds and travel compensation from Biogen Idec, Merck Serono, Novartis, Sanofi-Genzyme and Roche. His research is funded by Deutsche Forschungsgesellschaft (DFG) and Hertie Foundation.

SGM receives honoraria for lecturing, and travel expenses for attending meetings from Almirall, Amicus Therapeutics Germany, Bayer Health Care, Biogen, Celgene, Diamed, Genzyme, MedDay Pharmaceuticals, Merck Serono, Novartis, Novo Nordisk, ONO Pharma, Roche, Sanofi-Aventis, Chugai Pharma, QuintilesIMS and Teva. His research is funded by the German Ministry for Education and Research (BMBF), Deutsche Forschungsgesellschaft (DFG), Else Kröner Fresenius Foundation, German Academic Exchange Service, Hertie Foundation, Interdisciplinary Center for Clinical Studies (IZKF) Muenster, German Foundation Neurology and Almirall, Amicus Therapeutics Germany, Biogen, Diamed, Fresenius Medical Care, Genzyme, Merck Serono, Novartis, ONO Pharma, Roche, and Teva.

The other co-authors declare no competing financial interests. 


\section{SiquNAis}

\begin{tabular}{l}
\hline Neurosignals 2018;26:77-93 \\
\begin{tabular}{l|l}
\hline DOI: $10.1159 / 000495425$ & c 2018 The Author(s). Published by S. Karger AG, Basel \\
Published online: November 26, 2018 & www.karger.com/nsg
\end{tabular} \\
\hline
\end{tabular}

Hundehege et al.: Pregabalin in Experimental Autoimmune Encephalitis

\section{References}

1 Noseworthy JH, Lucchinetti C, Rodriguez M, Weinshenker BG: Multiple sclerosis. N Engl J Med 2000;343:938-952.

-2 Baecher-Allan C, Kaskow BJ, Weiner HL: Multiple Sclerosis: Mechanisms and Immunotherapy. Neuron 2018;97:742-768.

-3 Montalban X, Hauser SL, Kappos L, Arnold DL, Bar-Or A, Comi G, de Seze J, Giovannoni G, Hartung HP, Hemmer B, Lublin F, Rammohan KW, Selmaj K, Traboulsee A, Sauter A, Masterman D, Fontoura P, Belachew S, Garren H, Mairon N, Chin P, Wolinsky JS, Investigators OC: Ocrelizumab versus Placebo in Primary Progressive Multiple Sclerosis. N Engl J Med 2017;376:209-220.

4 Bittner S, Ruck T, Wiendl H, Grauer OM, Meuth SG: Targeting B cells in relapsing-remitting multiple sclerosis: from pathophysiology to optimal clinical management. Ther Adv Neurol Disord 2017;10:51-66.

5 Liu S, Zwinger P, Black JA, Waxman SG: Tapered withdrawal of phenytoin removes protective effect in EAE without inflammatory rebound and mortality. J Neurol Sci 2014;341:8-12.

6 Shields SD, Butt RP, Dib-Hajj SD, Waxman SG: Oral administration of PF-01247324, a subtypeselective Nav1.8 blocker, reverses cerebellar deficits in a mouse model of multiple sclerosis. PLoS One 2015; 10:e0119067.

7 Shields SD, Cheng X, Gasser A, Saab CY, Tyrrell L, Eastman EM, Iwata M, Zwinger PJ, Black JA, Dib-Hajj SD, Waxman SG: A channelopathy contributes to cerebellar dysfunction in a model of multiple sclerosis. Ann Neurol 2012;71:186-194.

8 Black JA, Liu S, Carrithers M, Carrithers LM, Waxman SG: Exacerbation of experimental autoimmune encephalomyelitis after withdrawal of phenytoin and carbamazepine. Ann Neurol 2007;62:21-33.

9 Kostic M, Zivkovic N, Stojanovic I: Multiple sclerosis and glutamate excitotoxicity. Rev Neurosci 2013;24:7188.

10 Luoma JI, Kelley BG, Mermelstein PG: Progesterone inhibition of voltage-gated calcium channels is a potential neuroprotective mechanism against excitotoxicity. Steroids 2011;76:845-855.

11 Szydlowska K, Tymianski M: Calcium, ischemia and excitotoxicity. Cell Calcium 2010;47:122-129.

-12 Joshi I, Taylor CP: Pregabalin action at a model synapse: Binding to presynaptic calcium channel alpha(2)delta subunit reduces neurotransmission in mice. Eur J Pharmacol 2006;553:82-88.

13 Silverman RB: From basic science to blockbuster drug: the discovery of Lyrica. Angewandte Chemie 2008;47:3500-3504.

14 Klugbauer N, Marais E, Hofmann F: Calcium channel alpha2delta subunits: differential expression, function, and drug binding. Journal of bioenergetics and biomembranes 2003;35:639-647.

15 Cassidy JS, Ferron L, Kadurin I, Pratt WS, Dolphin AC: Functional exofacially tagged N-type calcium channels elucidate the interaction with auxiliary alpha2delta-1 subunits. Proc Natl Acad Sci U S A 2014;111:8979-8984.

16 Dolphin AC: Voltage-gated calcium channels and their auxiliary subunits: physiology and pathophysiology and pharmacology. J Physiol-London 2016;594:5369-5390.

17 Fehrenbacher JC, Taylor CP, Vasko MR: Pregabalin and gabapentin reduce release of substance P and CGRP from rat spinal tissues only after inflammation or activation of protein kinase C. Pain 2003;105:133-141.

18 Taylor CP, Angelotti T, Fauman E: Pharmacology and mechanism of action of pregabalin: the calcium channel alpha2-delta (alpha2-delta) subunit as a target for antiepileptic drug discovery. Epilepsy Res 2007;73:137-150.

19 Catterall WA: Structure and regulation of voltage-gated Ca2+ channels. Annu Rev Cell Dev Biol 2000;16:521-555.

20 Hofmann F, Lacinova L, Klugbauer N: Voltage-dependent calcium channels: From structure to function. Rev Physiol Bioch P 1999;139:33-87.

21 Dolphin AC: Calcium channel auxiliary alpha2delta and beta subunits: trafficking and one step beyond. Nat Rev Neurosci 2012;13:542-555.

22 Dolphin AC: Voltage-gated calcium channels and their auxiliary subunits: physiology and pathophysiology and pharmacology. J Physiol 2016;594:5369-5390.

23 Platzer J, Engel J, Schrott-Fischer A, Stephan K, Bova S, Chen H, Zheng H, Striessnig J: Congenital deafness and sinoatrial node dysfunction in mice lacking class D L-type Ca2+ channels. Cell 2000;102:89-97. 
24 Catterall WA: Voltage-gated calcium channels. Cold Spring Harbor perspectives in biology 2011;3:a003947.

25 Meuth SG, Kanyshkova T, Landgraf P, Pape HC, Budde T: Influence of Ca2+-binding proteins and the cytoskeleton on Ca2+-dependent inactivation of high-voltage activated Ca2+ currents in thalamocortical relay neurons. Pflugers Arch 2005;450:111-122.

-26 Budde T, Meuth S, Pape HC: Calcium-dependent inactivation of neuronal calcium channels. Nat Rev Neurosci 2002;3:873-883.

27 Davenport B, Li Y, Heizer JW, Schmitz C, Perraud AL: Signature Channels of Excitability no More: L-Type Channels in Immune Cells. Front Immunol 2015;6:375.

-28 Emmez H, Borcek AO, Kaymaz M, Kaymaz F, Durdag E, Civi S, Gulbahar O, Aykol S, Pasaoglu A: Neuroprotective effects of gabapentin in experimental spinal cord injury. World Neurosurg 2010;73:729734.

29 Kale A, Borcek AO, Emmez H, Yildirim Z, Durdag E, Lortlar N, Kurt G, Dogulu F, Kilic N: Neuroprotective effects of gabapentin on spinal cord ischemia-reperfusion injury in rabbits. J Neurosurg Spine 2011;15:228-237.

-30 Moriya S, Hasegawa M, Inamasu J, Kogame H, Hirose Y, Higashi R, Ito M, Imai F: Neuroprotective effects of pregabalin in a rat model of intracisternal facial nerve avulsion. Journal of neurosurgical sciences 2017;61:495-503.

31 Traa BS, Mulholland JD, Kadam SD, Johnston MV, Comi AM: Gabapentin neuroprotection and seizure suppression in immature mouse brain ischemia. Pediatr Res 2008;64:81-85.

32 Gobel K, Pankratz S, Schneider-Hohendorf T, Bittner S, Schuhmann MK, Langer HF, Stoll G, Wiendl H, Kleinschnitz C, Meuth SG: Blockade of the kinin receptor B1 protects from autoimmune CNS disease by reducing leukocyte trafficking. Journal of autoimmunity 2011;36:106-114.

-33 Meuth SG, Herrmann AM, Ip CW, Kanyshkova T, Bittner S, Weishaupt A, Budde T, Wiendl H: The two-pore domain potassium channel TASK3 functionally impacts glioma cell death. J Neuro-Oncol 2008;87:263-270.

-34 Pfaffl MW: A new mathematical model for relative quantification in real-time RT-PCR. Nucleic Acids Res 2001;29:e45.

-35 Pfaffl MW, Horgan GW, Dempfle L: Relative expression software tool (REST) for group-wise comparison and statistical analysis of relative expression results in real-time PCR. Nucleic Acids Res 2002;30:e36.

-36 Pankratz S, Bittner S, Herrmann AM, Schuhmann MK, Ruck T, Meuth SG, Wiendl H: Human CD4+ HLA-G+ regulatory T cells are potent suppressors of graft-versus-host disease in vivo. FASEB J 2014;28:3435-3445.

37 Ruck T, Bittner S, Epping L, Herrmann AM, Meuth SG: Isolation of primary murine brain microvascular endothelial cells. J Vis Exp 2014:e52204.

38 Ghaffarian N, Mesgari M, Cerina M, Gobel K, Budde T, Speckmann EJ, Meuth SG, Gorji A: Thalamocorticalauditory network alterations following cuprizone-induced demyelination. J Neuroinflammation 2016;13:160.

-39 Duffy SS, Lees JG, Moalem-Taylor G: The contribution of immune and glial cell types in experimental autoimmune encephalomyelitis and multiple sclerosis. Mult Scler Int 2014;2014:285245.

40 Zuccotti A, Clementi S, Reinbothe T, Torrente A, Vandael DH, Pirone A: Structural and functional differences between L-type calcium channels: crucial issues for future selective targeting. Trends in Pharmacological Sciences 2011;32:366-375.

41 Abbott NJ, Patabendige AA, Dolman DE, Yusof SR, Begley DJ: Structure and function of the blood-brain barrier. Neurobiol Dis 2010;37:13-25.

42 Engelhardt B, Ransohoff RM: Capture, crawl, cross: the T cell code to breach the blood-brain barriers. Trends Immunol 2012;33:579-589.

43 Han YY, Wang XD, Liu L, Guo HM, Cong W, Yan WW, Huang JN, Xiao P, Li CH: L-type VDCCs participate in behavioral-LTP and memory retention. Neurobiol Learn Mem 2017;145:75-83.

44 Siffrin V, Radbruch H, Glumm R, Niesner R, Paterka M, Herz J, Leuenberger T, Lehmann SM, Luenstedt S, Rinnenthal JL, Laube G, Luche H, Lehnardt S, Fehling HJ, Griesbeck O, Zipp F: In vivo imaging of partially reversible th17 cell-induced neuronal dysfunction in the course of encephalomyelitis. Immunity 2010;33:424-436.

45 Nikic I, Merkler D, Sorbara C, Brinkoetter M, Kreutzfeldt M, Bareyre FM, Bruck W, Bishop D, Misgeld T, Kerschensteiner M: A reversible form of axon damage in experimental autoimmune encephalomyelitis and multiple sclerosis. Nat Med 2011;17:495-499. 


\section{SIGiNAis}

Neurosignals 2018;26:77-93

\begin{tabular}{l|l}
\hline DOI: 10.1159/000495425 & C 2018 The Author(s). Published by S. Karger AG, Basel \\
Published online: November 26, 2018 & www.karger.com/nsg
\end{tabular}

Hundehege et al.: Pregabalin in Experimental Autoimmune Encephalitis

46 McKinney RA, Luthi A, Bandtlow CE, Gahwiler BH, Thompson SM: Selective glutamate receptor antagonists can induce or prevent axonal sprouting in rat hippocampal slice cultures. P Natl Acad Sci USA 1999;96:11631-11636.

47 Nitsch R, Pohl EE, Smorodchenko A, Infante-Duarte C, Aktas O, Zipp F: Direct impact of T cells on neurons revealed by two-photon microscopy in living brain tissue. J Neurosci 2004;24:2458-2464.

48 Haghmorad D, Mahmoudi MB, Mahmoudi M, Rab SZ, Rastin M, Shegarfi H, Azizi G, Mirshafiey A: Calcium intervention ameliorates experimental model of multiple sclerosis. Oman Med J 2014;29:185-189.

-49 Ingwersen J, De Santi L, Wingerath B, Graf J, Koop B, Schneider R, Hecker C, Schroter F, Bayer M, Engelke AD, Dietrich M, Albrecht P, Hartung HP, Annunziata P, Aktas O, Prozorovski T: Nimodipine confers clinical improvement in two models of experimental autoimmune encephalomyelitis. J Neurochem 2018

50 Silva RBM, Greggio S, Venturin GT, da Costa JC, Gomez MV, Campos MM: Beneficial Effects of the Calcium Channel Blocker CTK 01512-2 in a Mouse Model of Multiple Sclerosis. Mol Neurobiol 2018

51 Silva GA, Pradella F, Moraes A, Farias A, dos Santos LM, de Oliveira AL: Impact of pregabalin treatment on synaptic plasticity and glial reactivity during the course of experimental autoimmune encephalomyelitis. Brain Behav 2014;4:925-935.

52 Fairless R, Williams SK, Diem R: Dysfunction of neuronal calcium signalling in neuroinflammation and neurodegeneration. Cell Tissue Res 2014;357:455-462.

53 Chan SL, Mattson MP: Caspase and calpain substrates: roles in synaptic plasticity and cell death. J Neurosci Res 1999;58:167-190.

54 Kilinc D, Gallo G, Barbee KA: Mechanical membrane injury induces axonal beading through localized activation of calpain. Exp Neurol 2009;219:553-561.

55 Mahad DJ, Ziabreva I, Campbell G, Lax N, White K, Hanson PS, Lassmann H, Turnbull DM: Mitochondrial changes within axons in multiple sclerosis. Brain 2009;132:1161-1174.

-56 Starkov AA, Chinopoulos C, Fiskum G: Mitochondrial calcium and oxidative stress as mediators of ischemic brain injury. Cell Calcium 2004;36:257-264.

57 Stojanovic IR, Kostic M, Ljubisavljevic S: The role of glutamate and its receptors in multiple sclerosis. J Neural Transm (Vienna) 2014;121:945-955.

58 McKee JB, Elston J, Evangelou N, Gerry S, Fugger L, Kennard C, Kong Y, Palace J, Craner M: Amiloride Clinical Trial In Optic Neuritis (ACTION) protocol: a randomised, double blind, placebo controlled trial. BMJ Open 2015;5:e009200.

59 McKee JB, Elston J, Evangelou N, Gerry S, Fugger L, Kennard C, Koelewyn A, Kong Y, Cottriall C, Palace J, Craner M: Amiloride does not protect retinal nerve fibre layer thickness following acute optic neuritis; result from a phase II, double blind, randomised controlled trial. Mult Scler J 2016;22:21-22.

60 Connick P, Miller D, Pavitt S, Giovannoni G, Wheeler-Kingshott C, Weir C, Stallard N, Hawkins C, Sharrack B, Cranswick G, Chandran S, Chataway J, Trialists M-S: MS-SMART trial design and recruitment status: a multiarm phase IIB randomised double blind placebo-controlled clinical trial comparing the efficacy of three repositioned neuroprotective drugs in secondary progressive multiple sclerosis. Mult Scler J 2016;22:630631.

61 De Angelis F, Cameron J, Connick P, Miller D, Pavitt S, Giovannoni G, Wheeler-Kingshott CG, Plantone D, Doshi A, Weir C, Parker R, Stallard N, Hawkins C, Sharrack B, Cranswick G, Chandran S, Chataway J, Trialists M-S: Optical coherence tomography in secondary progressive multiple sclerosis: a baseline data report from the MS-SMART trial. Mult Scler J 2016;22:250-251.

62 Green AJ, Gelfand JM, Cree BA, Bevan C, Boscardin WJ, Mei F, Inman J, Arnow S, Devereux M, Abounasr A, Nobuta H, Zhu A, Friessen M, Gerona R, von Budingen HC, Henry RG, Hauser SL, Chan JR: Clemastine fumarate as a remyelinating therapy for multiple sclerosis (ReBUILD): a randomised, controlled, doubleblind, crossover trial. Lancet 2017;390:2481-2489.

63 Saidha S, Calabresi PA: Phenytoin in acute optic neuritis: neuroprotective or not? Lancet Neurol 2016;15:233-235. 